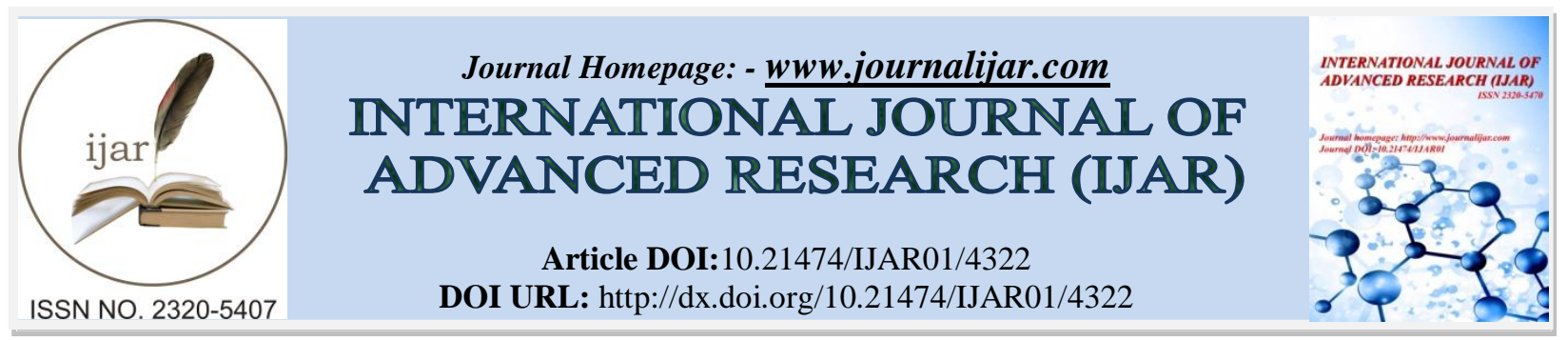

RESEARCH ARTICLE

\title{
CYTOMEGALOVIRUS INFECTION IN CRITICALLY ILL PATIENT.
}

Guliko Kiliptari $^{1}$,Tamar Didbaridze ${ }^{2}$, Nino Gogokhia ${ }^{3}$ and Khatia Mikaberidze ${ }^{4}$.

1. Head of Department of critical care MD, PhD. TSMU the First University Clinic (Tbilisi, Georgia).

2. Microbiologist.TSMU the First University Clinic. MD, PhD (Tbilisi, Georgia).

3. Head of Clinical Laboratory.TSMU the first University Clinic(Tbilisi,Georgia).

4. Laboratory Physitian.TSMU the First University Clinic(Tbilisi, Georgia).

\section{Manuscript Info}

Manuscript History

Received: 23 March 2017

Final Accepted: 28 April 2017

Published: May 2017

Key words:-

CMV( Cytomegalovirus),reactivation.

\section{Abstract}

The role of cytomegalovirus infection in contributing to outcomes in critically ill immunocompetent patient has not been fully defined. Active infection is observed in ICU patients and in more the $20 \%$ of ICU patient - positive serology .More studies are needed to identify factors that could predict the risk of developing a CMV reactivation, mechanism causing CMV pathogenicity and predisposing immunologic conditions associated with the development of CMV reactivation. Clinically significant CMV disease (reactivation of previously latent infection or newly acquired infection) frequently develops in immunocompromised patients . Cytomegalovirus can cause a wide spectrum of infection in immunocompetent hosts and multisystem involvement (fever of unknown origin). The case of cytomegalovirus activation in immunocompetent patient is presented. The case challenges diagnosis and identification of CMV and patient management.

Copy Right, IJAR, 2017,. All rights reserved.

\section{Introduction:-}

Cytomegalovirus is major $\beta$ herpes virus an human pathogen a double-stranded DNA virus and a member of the Herpesviridae family. The other family members include herpes simplex virus type 1 and herpes simplex virus type 2 , varicella zoster virus (VZV), human herpes virus (HHV)-6, HHV-7, and HHV-8(1,2).

Clinically significant CMV disease (reactivation of previously latent infection or newly acquired infection) frequently develops in patients immunocompromised by HIV infection, solid-organ transplantation, or bone marrow transplantation, as well as in those receiving high-dose steroids, tumor necrosis antagonists, or other immunosuppressing medications for conditions such as systemic lupus erythematosus rheumatoid arthritis, Crohn disease, or psoriasis, among others $(4,5,6)$.

CMV can cause a wide spectrum of infection in immunocompetent hosts,severe community-acquired viral pneumonia, liver (transaminitis), spleen (splenomegaly), GI tract (colitis), CNS (encephalitis), hematologic system (cytopenias), and multisystem involvement (fever of unknown origin). Uncommon sites of CMV infections in immunocompetent individuals include the kidneys, adrenals, salivary glands, pancreas, and esophagus $(7,8,9,10)$.

Corresponding Author:-Guliko Kiliptari.

Address:-Head of Department of critical care MD, PhD. TSMU the First University Clinic (Tbilisi, Georgia). 
The lung is maior organ involved in active CMV infection with end organ disease. There are no specific clinical signs There is no radiological specificity .Sepsis,blood transfusion, corticosteroids ,ARDS have been associated with the risk of CMV reactivation $(11,12,13)$

CMV pneumonia is defined as signs and symptoms of pulmonary disease in combination with detection of CMV in bronchoalveolar fluid or lung tissue(14). CMV detection should be performed via culture, histopathology, immunohistochemical analysis, CMV DNA PCR testing alone is too sensitive for diagnosing CMV pneumonia(15).

\section{Case Report:-}

32 year old man.caucasion,was admitted in ICU after vehicle accident. Diagnosis:polytrauma,head closed trauma ,brain contusion, acute subarachnoid haemorrhage, scalped wound in temporal and parietal area. Closed chest trauma, lung contusion, fracture of shoulder bone, multiple and open fracture of shin bone. Excoriation of chest,abdomen,pelvic ,both extremities area,multiple subcutaneous hematomas.

At admission patient was in coma (GCS 4-5),hemodynamia was unstable and was used norepinephrin infusion .In operating room have been performed scalped wound surgical treatment and left shin osteosinthesis .

Chest CT revealed bilateral lung contusion. From second day of admission developed hyperthermia $>39$ $40^{\circ} \mathrm{C}$, leicocytosis $\left(20 \mathrm{X} 10^{9} / \mathrm{l}\right)$ and rash on full body surface. After one week. On second CT scan of chest revealed bilateral, dorsal infiltration in lung parenchyma.(picture N1)

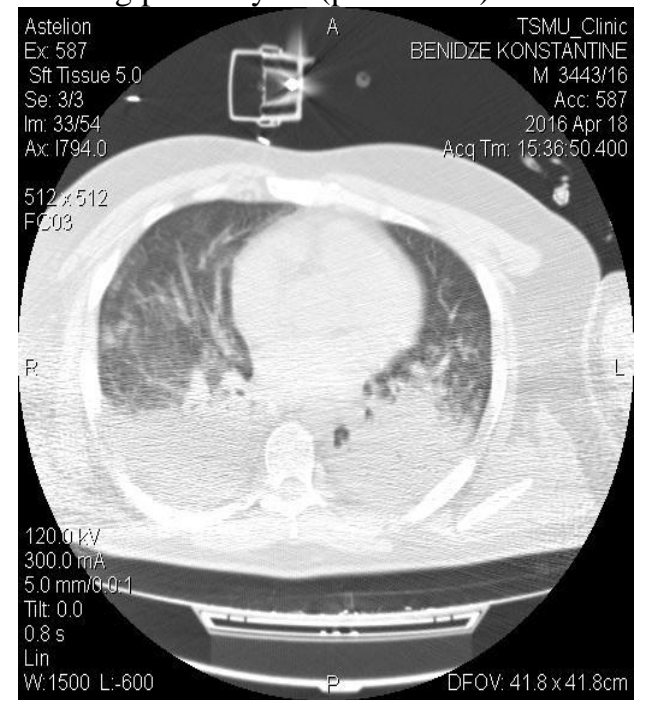

picture N1:-

On seven day after admission was identified Nocardia $\mathbf{s p p . X 1 0} / \mathbf{I}$ insputum.

Blood culture analisis revealed Staphylococcus aureus $\mathbf{X 1 0}^{\mathbf{8}}$ /l.From phlegmon of femoral soft tissue also was identified Nocardia spp.X10 $/ \mathbf{l}$. Sputum, urine, wound culture detected hospital pathogens on different time, pseudomonas aeruginosa and others.

Antibacterial treatment was based on datas of microbial susceptibility tests . Regardless of suitable treatment, patient state was worsened .Developed Repiratory distress syndrom, hepatic desfunction,acute renal failure,permanent hyperthermia .On twentieth day after admission was investigated blood for CMV detection. By CMV DNA PCR quantitative testing was revealed CMV - 1812 copies $/ \mathbf{m l}$.

Patient was treated with ganciclovir $5 \mathrm{mg} / \mathrm{kg}$ twice a day within 2 week. From fifth day after treatment patient state was improved, temperature decreased, respiratory parameters was normalized.

There is no absolute direct proof of a negative impact of active CMV infection on the health outcomes of mechanically ventilated patients. Prospective randomized trials are lacking. Future trials should examine the potential benefits for health outcomes of using antiviral treatments. Such treatments could be prophylactic, preemptive or used only when there is an end-organ disease. Cytomegalovirus infection may affect health outcomes 
for ICU patients. Additional prospective trials are necessary to confirm this hypothesis. The potential harms and benefits of antiviral treatment have to be weighed very cautiously in patients with severe sepsis or septic shock.

\section{Conclusion:-}

In case of 32 yars old man, the diagnosis of CMV reactivation was established by blood investigation. Cytomegalovirus can be pathogenic by decreasing host defences against other microorganisms, enhancing inflammatory response. There is dilemma, to treat or not to treat? Some randomized controlled trials evaluated the effectiveness of an antiviral therapy and one study to show increased the number of day free of mechanical ventilation.This case presented diagnoisis and identification of CMV, patient management and and effectiveness of an ativiral therapy in improving outcomes.

\section{References:-}

1. Cunha BA. Cytomegalovirus pneumonia: community-acquired pneumonia in immunocompetent hosts. Infect Dis Clin North Am. 2010 Mar. 24(1):147-58

2. Orlikowski D, Porcher R, Sivadon-Tardy V, et al. Guillain-Barre Syndrome following Primary Cytomegalovirus Infection: A Prospective Cohort Study. Clin Infect Dis. 2011 Apr. 52(7):837-44.

3. Klemola E, Stenström R, von Essen R. Pneumonia as a clinical manifestation of cytomegalovirus infection in previously healthy adults. Scand J Infect Dis. 1972. 4(1):7-10.

4. Jaber S, Chanques G, Borry J, Souche B, Verdier R, Perrigault PF. Cytomegalovirus infection in critically ill patients: associated factors and consequences. Chest. 2005 Jan.

5. Müller L, Klemm A, Weiss M, et al. Active cytomegalovirus infection in patients with septic shock. Emerg Infect Dis. 2006 Oct. 12(10):1517-22. [Medline]

6. Caldés A, Gil-Vernet S, Armendariz Y, Colom H, Pou L, Niubó J, et al. Sequential treatment of cytomegalovirus infection or disease with a short course of intravenous ganciclovir followed by oral valganciclovir: efficacy, safety, and pharmacokinetics. Transpl Infect Dis. 2009 Dec 9. [Medline].

7. Jaber S, Chanques G, Borry J, Souche B, Verdier R, Perrigault PF, Eledjam JJ (2005) Cytomegalovirus infection in critically ill patients: associated factors and consequences. Chest 127:233-241

8. Brenner T, Rosenhagen C, Hornig I, Schmidt K, Lichtenstern C, Mieth M, Bruckner T, Martin E, Schnitzler P, Hofer S, Weigand MA (2012) Viral infections in septic shock (VISS-trial)-crosslinks between inflammation and immunosuppression. J Surg Res 176:571-58

9. Heininger A, Haeberle H, Fischer I, Beck R, Riessen R, Rohde F, Meisner C, Jahn G, Koenigsrainer A, Unertl K, Hamprecht K (2011) Cytomegalovirus reactivation and associated outcome of critically ill patients with severe sepsis. Crit Care 15:R77

10. Kalil AC, Florescu DF (2009) Prevalence and mortality associated with cytomegalovirus infection in nonimmunosuppressed patients in the intensive care unit. Crit Care Med 37:2350-2358

11. Kalil AC, Florescu DF (2011) Is cytomegalovirus reactivation increasing the mortality of patients with severe sepsis? Crit Care 15:138

12. Limaye AP, Kirby KA, Rubenfeld GD, Leisenring WM, Bulger EM, Neff MJ, Gibran NS, Huang ML, Santo Hayes TK, Corey L, Boeckh M (2008) Cytomegalovirus reactivation in critically ill immunocompetent patients. JAMA 300:413-422

13. Osawa R, Singh N (2009) Cytomegalovirus infection in critically ill patients: a systematic review. Crit Care 13:R68

14. Kutza AS, Muhl E, Hackstein H, Kirchner H, Bein G (1998) High incidence of active cytomegalovirus infection among septic patients. Clin Infect Dis 26:1076-1082CrossRefPubMedGoogle Scholar

15. Laurent Papazian Samuel Lehingue, Antoine Roch, Laurent Chiche, Sandrine Wiramus, JeanMarie Forel.Cytomegalovirus reactivation in ICU patients.Intensive Care MedicineJanuary 2016, Volume 42, Issue 1 , pp 28-37 